\title{
Is it possible to improve early childhood development with a video-feedback intervention directed at the mother-father-child triad?
}

\author{
Marcia Olhaberry, ${ }^{1}$ María José León, ${ }^{2}$ Catalina Sieverson, ${ }^{2}$ Marta Escobar, ${ }^{1}$ Daniela Iribarren, ${ }^{1}$ Irma Morales-Reyes, ${ }^{1}$ \\ Constanza Mena, ${ }^{1}$ Fanny Leyton ${ }^{1}$
}

${ }^{1}$ School of Psychology, Pontifical Catholic University of Chile, Santiago; ${ }^{2}$ Faculty of Medicine, University of Chile, Santiago, Chile

\begin{abstract}
Relationships with primary caregivers provide the context for early childhood development, and evaluating those relationships during the early years can detect difficulties that may influence future mental health. Video feedback is a valuable intervention tool in early childhood, both for family relationships and child development. An intervention was implemented using this technique, focused on mother-father-child triads that were experiencing difficulties in social-emotional development. Participants were 80 mother-fatherinfant triads (experimental group, $\mathrm{EG}=40$, control group, $\mathrm{CG}=40$ ), with children between 1 and 3 years old. Socio-emotional difficulties decreased significantly in the children who received the intervention (Wilks $\lambda=0.930, \mathrm{~F}(1,78)=5.907$; $\mathrm{P}=.017$ ). There was also an increase in psychomotor development in communication (Wilks $\lambda=0.948, \mathrm{~F}(1,78)=4.284 ; \mathrm{P}=.042$ ) and fine motor skills (Wilks $\lambda=0.875$, $\mathrm{F}(1,78)=11.185 ; \mathrm{P}=.001)$ in children in the $\mathrm{EG}$ compared with children in the CG.
\end{abstract}

Correspondence: Marcia Olhaberry, School of Psychology, Pontifical Catholic University of Chile, Av. Vicuña Mackena 4860, Macul, Santiago, Chile.

Tel.: 56223547579 .

E-mail: mpolhabe@uc.cl

Citation: Olhaberry, M., León, M. J., Sieverson, C., Escobar, M., Iribarren, D., Morales-Reyes, I., ... Leyton, F. (2019). Is it possible to improve early childhood development with a video-feedback intervention directed at the mother-father-child triad? Research in Psychotherapy: Psychopathology, Process and Outcome, 22(2), 244-255. doi: 10.4081/ripppo.2019.324

Contributions: MO participated and led different phases of the research and writing process; MJL, CS, ME, DI participated in the research and writing process; FL participated in the writing process; IM-R contributed to the analysis; $\mathrm{CM}$ contributed to the analysis and literature review.

Conflict of interest: the authors declare no potential conflict of interest.

Funding: this work was supported by the National Commission for Scientific and Technological Research, CONICYT (Comisión Nacional de Investigación Científica y Tecnológica), Chile; the Fondecyt Initiation Project No. 11140230; the Innovation Fund for Competitiveness of the Ministry of Economy, Development and Tourism (Ministerio de Economía, Fomento y Turismo); and finally, the Millennium Institute for Research on Depression and Personality, MIDAP (Instituto Milenio para la Investigación en Depresión y Personalidad), Project IS130005.

Received for publication: 29 July 2018.

Revision received: 18 February 2019.

Accepted for publication: 25 March 2019.

This work is licensed under a Creative Commons Attribution NonCommercial 4.0 License (CC BY-NC 4.0).

${ }^{\circ}$ Copyright: the Author(s), 2019

Licensee PAGEPress, Italy

Research in Psychotherapy:

Psychopathology, Process and Outcome 2019; 22:244-255

doi:10.4081/ripppo.2019.324
Key words: Child development; Socio-emotional development; Early intervention; Triadic interaction; Video-feedback intervention.

\section{Introduction}

The early years of life constitute a valuable opportunity to lay the foundations of child development, as well to intervene when children present early developmental difficulties. Nowadays, the prevalence of child socialemotional and psychomotor problems continues to be high. Several studies on early childhood development have shown that $11 \%$ to $37 \%$ of children tend to present risk levels of social-emotional development (Bian, Xie, Squires, \& Chen, 2017; Briggs et al., 2012; BriggsGowan et al., 2013; Squires, Bricker, \& Twombly, 2014; Wendland et al., 2014). Regarding psychomotor development - which typically includes communicative, cognitive and motor skills - approximately $69 \%$ of children between 0 and 66 months demonstrated typical development, $7.4 \%$ presented risk in one area, and $23.6 \%$ presented risk in two or three areas (Squires et al., 2014).

Chilean studies reported significant difficulties in psychomotor development during early childhood, with $17.4 \%$ of children being monitored for risk and between $7.2 \%$ and $12.73 \%$ of children under 2 years of age considered delayed (Centro de Microdatos-Universidad de Chile, 2010; Schonhaut et al., 2010; Schonhaut \& Armijo, 2014). Similarly, studies indicate that the socio-emotional difficulties of Chilean children tend to increase with age, with $17.1 \%$ at risk at 12 months and $24.2 \%$ at 18 months 
of age. Subsequently, between 18 and 60 months, 10.8\% of the children had clinically significant socio-emotional difficulties. However, analyzing these figures according to socioeconomic level indicated that lower family income was associated with greater difficulties in children's socio-emotional development (Centro de MicrodatosUniversidad de Chile, 2010, 2014).

Therefore, parents' ability to identify early difficulties in their children's development can be a protective factor, as their denial and/or normalization may create more severe problems in the future. Timely and accurate identification of problems in early childhood development, often associated with mental health, is the first step toward early intervention, favoring effective outcomes for children, their families and communities (Squires, Bricker, \& Twombly, 2004). However, few studies indicate the optimal age at which to detect these problems (Caselman \& Self, 2008; De Wolff, Theunissen, Vogels, \& Reijneveld, 2013; Schonhaut \& Armijo, 2014).

Between birth and three years of age, important achievements occur in cognitive, linguistic, social, emotional and psychomotor development (Shonkoff, Phillips, \& National Research Council, 2000; Thompson, 2001). At nearly two years of age, an explosive increase is expected in children's vocabulary and in children's ability to identify emotions in themselves and in others and to regulate their own emotions (Cicchetti, 1990; Papalia \& Feldman, 2012). At this stage, a nurturing environment and responsive parenting will promote healthy development, whilst at-risk contexts can negatively affect child development (Hart \& Risley, 1995; Sirin, 2005).

According to the child development literature, there is worldwide consensus that the acquisition of social-emotional skills occurs simultaneously with the achievement of skills such as motor control, reasoning and communication (Thompson, 2001). Some authors noted that child development depends on constitutional, maturational and environmental variables and that each stage can be understood as the result of specific patterns of interaction between the caregiver and the child (Greenspan, 2007; Greenspan, DeGangu, \& Wieder, 2001). In the same sense, Benz and Scholtes-Spang (2015), proposed that one of the primary early childhood development milestones is achieving emotional regulation, which occurs in the early interactions with caregivers and is the key to successful development. Many studies have shown how a positive early mother-child interaction can positively influence the child's psychomotor development (Bouvette-Turcot, Bernier, \& Leblanc, 2017; Planalp \& Braungart-Rieker, 2013), social-emotional development (Briggs-Gowan, Carter, Irwin, Wachtel, \& Cicchetti, 2004; Kim, 2012; Riera, 2016; Salomonsson, Sorjonen, \& Salomonsson, 2015), and mental health (Sidor, Fischer, Eickhorst, \& Cierpka, 2013).

Triadic relationships play an important role in helping the child achieve some of the main developmental tasks such as acquiring social skills and learning to be au- tonomous (Fincham, 1998; Parke, 1996; Sroufe, 1996). In the interaction with their parents the child learns to create and maintain relationships involving more than two people, he learns to share affection, attention and a common goal among three people, learning to address feelings of exclusion associated with the development of greater social skills (Fivaz-Depeursinge \& Corboz-Warnery, 1999). Therefore, reciprocal relations with the mother, involvement with the father and family cohesion in the triad have been described as predictors of adequate child social skills (Feldman \& Masalha, 2010). In addition, cooperative interactions within the mother-father-child triad during the first years of life are positive experiences for children that enhance their social development (Leidy, Schofield, \& Parke, 2013; Raikes \& Thompson, 2006; Teubert \& Pinquart, 2010).

In this regard, Engfer (1988) formulated the spillover hypothesis, referring to the effects of the marital couple on the parent-child subsystem. For example, marital conflicts may affect each caregiver's experience of parenting and thus coparenting (Tissot, Favez, Frascarolo, \& Despland, 2016). Subsequently, it has been described that the involvement of children in chronic dysfunctional interactions and family interactions with conflicted parents hinders the development of adaptive conflict management skills and is associated with flaws in regulatory mechanisms and greater difficulties in peer relationships (Cummings \& Davies, 2010; McHale, 2007).

The clinical experience and research using Lausanne Trialogue Play (LTP), show that its use might constitute an intervention tool, as well as an instrument that assesses family interactions. In this sense, it fulfills a double function, it allows to observe and assess verbal and non-verbal aspects of the interaction, while promoting family development. Its clinical use considers video-recording of the interactions and video-feedback sessions which allow families to incorporate new perspectives of what they have experienced, including their own subjective experience and the possibility of observing themselves, others and their interactions with some distance (McHale, Favez, $\&$ Fivaz-Depeursinge, 2018).

\section{Video feedback as a family intervention tool in early childhood}

Various studies have obtained positive outcomes regarding the use of video-feedback as an intervention tool, supporting its effectiveness in improving and promoting child development and mental health, and the quality of parent-child interactions (Bakermans-Kranenburg, van IJzendoorn, \& Juffer, 2003; Pontoppidan, 2015; Pontoppidan, Klest, \& Sandoy, 2016; Riera, 2016; Salomonsson et al., 2015). The two meta-analyses that studied the effects of video-feedback interventions concluded that in a few sessions, it is possible to achieve a moderate change in parenting skills (Bakermans-Kranenburg et al., 2003; Fukkink, 2008). 
Studies that specifically analyze the effect of video feedback on children's socio-emotional development present mixed results and are few compared with those analyzing parental variables or variables associated with parent-child interactions. Fukkink's meta-analysis -which reviews 28 studies conducted up to 2006 - concluded that video-feedback interventions have a statistically significant effect on changing children's behavior, with a small to medium effect size $(\mathrm{ES}=0.33, \mathrm{SD}=0.10)$. It also identified a moderating effect on high-risk families (with depressed, adolescent, low-income or single parents) in which the positive effects of video feedback were lower (Fukkink, 2008).

Clinical trials following this review reported the evaluation of outcomes in children in different settings and with varying effects. Moss et al. (2011) reported that a greater proportion of children in the video-feedback group changed their attachment pattern from insecure to secure and from a disorganized attachment to an organized pattern. It should be noted that although a direct effect of video-feedback on children is often not identified, various moderating effects have been analyzed and reported (Groeneveld, Vermeer, van Ijzendoorn, \& Linting, 2016; Hoivik et al., 2015; Kalinauskiene et al., 2009; Moss et al., 2011; Van Zeijl et al., 2006). Van Zeijl et al. (2006) observed that in the intervention group, hyperactivity significantly decreased in children from families with greater marital discord and daily problems. Moss et al. (2011) found that internalizing and externalizing problems diminished significantly as the children in the intervention group grew older, whereas problems in the control group increased with age. Groenveld et al. (2016) observed a moderating effect of the time spent with the caregiver while receiving the intervention, noting that the children's well-being in the intervention group significantly increased the more familiar they were with their caregiver. Hoivik et al. (2015) observed a delayed but substantial effect of video-feedback on social-emotional development, reporting that at a sixmonth follow-up the children in the intervention group had greater self-regulation, compliance, adaptive functioning, autonomy, affect, and interaction with others, as measured with the Ages and Stages Questionnaires-SE (ASQ-SE).

This technique has been used in Chile with mother-infant dyads exhibiting depressive symptoms, demonstrating improvements in caregivers' sensitivity to the child's needs (Olhaberry, León, Seguel, \& Mena, 2015), in dyads of low-income multiproblem families (Delucchi, Quinteros, Muzzio, \& Álvarez, 2009), as well as in triads where video-feedback interventions show favorable results on parental sensitivity and the quality of triadic interactions (Olhaberry et al., 2017).

Although video feedback is considered an evidencebased intervention, research on the mechanisms of change is limited. Doria, Kennedy, Strathie, and Strathie (2014) proposed that the key components of video feedback are the support and reception of the therapist, the observation of the recorded interactions, the focused approach to achievement and the recording of ensuing sessions as proof of change and success. Video-feedback interventions permits to modify underlying psychological mechanisms in the parents such as representations and beliefs, which facilitates that parent and children develop shared meanings about reality.

Considering the high prevalence of early childhood developmental difficulties, the value of video feedback as an early family psychotherapeutic tool, and the importance of a good childhood development, the present study assesses change in child psychomotor and social-emotional development after a video-feedback intervention for mother-father-child triads. It is hypothesized that socio-emotional and psychomotor development will significantly improve in children in the intervention group compared to the control group.

\section{Methods}

The study was part of a wider project that assessed mother-father-child triads pre- and post-intervention (Fondecyt de Iniciación $\mathrm{N}^{\circ} 11140230$, National Commission for Scientific and Technological Research, CONICYT, Chile). This study was certified by the ethics committees of the Pontifical Catholic University of Chile and the National Commission for Scientific and Technological Research (CONICYT).

The present study used a quasi-experimental design to evaluate the children's outcomes. The results from both control and experimental groups were compared before and after the intervention.

Data were collected during 2015 and 2016 by psychotherapists who were previously trained in the use of the tools. In the first contact with families, the parents were informed of the study's goals, and the inclusion and exclusion criteria were assessed. Families who met the criteria and were willing to participate in the study gave their informed consent, after which a home visit was arranged for data collection. Then, the first assessment session was video-recorded to measure the quality of triadic interactions using LTP (Fivaz-Depeursingue \& Corboz-Warnery, 1999) and dyadic interactions using CARE-Index (Crittenden, 2006; see results in Olhaberry et al., 2017), and scales and questions were completed. All couples completed the questionnaires together. The therapist registered their responses on the forms and both parents asked the child to complete the activities proposed in the Ages and Stages Questionnaires-3 (ASQ-3) questionnaire. Triads who required more treatment after the intervention was concluded were referred to public or private mental health services according to their place of origin. The professionals of these services were informed of the referrals. 


\section{Participants}

As mentioned above, families were recruited through professionals from JUNJI National Board of Preschools of the Ministry of Education of the Government of Chile nurseries and preschools, family public health centers and self-referrals.

Families with children (one to three years old) who presented socio-emotional difficulties as assessed by the ASQ-SE (Squires et al., 2014) from Santiago, Chile, were recruited through daycare and public health centers or referred by other participants. A total of 80 mother-fathertoddler triads participated in the study. Forty were assigned to the experimental group (EG) and were assessed before and after receiving a video-feedback intervention. The remaining forty families were assigned to the control group (CG) and received the video feedback intervention after being assessed twice, with a gap of approximately 5 weeks between assessments (see the study flowchart in Olhaberry et al., 2017).

The inclusion criteria for the study considered the following: parents were required to be at least 18 years old, currently in a heterosexual relationship, and have a child aged 12 to 36 months with socio-emotional difficulties reported by parents or the referrer. Difficulties were related to behavior, sleep, eating, emotion, and/or relationships. Parents with diagnosed psychosis and/or addictions and parents or children with disabilities were not included in the study. Parents were not assessed for other less severe psychiatric disorders such as depression or anxiety.

\section{Outcome measures}

The following measures were used.

\section{Personal information sheet}

This sheet was used to collect families' sociodemographic information such as the child's age, gender, birth order and number of siblings as well as parents' age, years of education, employment status, and any history of psychological/pharmacological treatment. The personal information sheet was answered by the parents only in the inital assessment.

\section{Ages and Stages Questionnaires-SE}

The ASQ-SE (Squires, Bricker, \& Twombly, 2003) was used for screening and monitoring social-emotional difficulties. It can be used with children from 3 months to 65 months of age. There are eight forms for each age range, and the number of items varies by form. The questionnaire is completed by the parent and scored according to the number of concerns the parent reports. In the current study, parents reported directly to the therapists who performed the intervention. Higher total scores indicated problems whereas low scores suggested that the child's social and emotional behaviour was considered appropriate by his or her parent. The instrument considers seven subscales: Self- regulation, Compliance, Communication, Adaptive Functioning, Autonomy, Affect and Interaction with People. Considering that the children participating in the study varied greatly in age, and that the scale uses different assessment templates according to age, it is not possible to compare the direct scores obtained. Thus, the degree of the problems of each child was calculated relative to the maximum for the child's age. The cut-off scores of the ASQ$\mathrm{SE}$ templates used a range from 12.69 to 14.54 . The average obtained in the study was 13.66 for the total sample of children, a score indicating significant difficulties in socio-emotional development. This instrument has a level of concurrent validity ranging from $71 \%-90 \%$, with an overall agreement of $84 \%$. Test-retest reliability is $89 \%$, and intra-class correlations were .91 (Squires, Bricker, \& Twombly, 2002). The questionnaires were answered by the parents in the pre- and post- intervention assessments.

\section{Ages and Stages Questionnaires-3}

The ASQ-3 (Squires, Twombly, Bricker, \& Potter, 2009 ) is used to screen young children for developmental delays, that is, to identify those children who are in need of further evaluation and those who appear to be developing normally. ASQ-3 has 21 questionnaires to use with children from 1 month to 5 and a half years of age addressing five developmental areas: Communication, Gross Motor, Fine Motor, Problem Solving and PersonalSocial. Each questionnaire contains 30 questions, grouped by developmental area, regarding a child's everyday activities. This instrument has a level of validity of $0.82-$ 0.88 , a test-retest reliability of 0.91 , and an inter-rater reliability of 0.92 (Squires et al., 2009). In Chile, a validation was developed, and the result shows adequate psychometric properties (sensitivity of $75 \%$, specificity of $81 \%, 54$ positive predictive value of $47 \%$, and negative predictive value of $9 \%$ ) and concurrent agreement compared with the Bayley-III (Schonhaut, Armijo, Schönstedt, Alvarez, \& Cordero, 2013). The questionnaires were answered by the parents in the pre- and post- intervention assessments.

\section{Characteristics of the interventions}

The video-feedback model used in this study was based on a previous intervention with mother-infant dyads exhibiting maternal depressive symptoms (Olhaberry et al., 2015), although certain elements were added to focus the intervention on triadic interactional aspects (Favez, Frascarolo, Keren, \& Fivaz-Depeursinge, 2009). The intervention was defined as triadic because both mothers and fathers participated with their child. However, participation of the parents varied according to each session, in some sessions they were active and in others they had a more passive role, participating through the images of the videos that were analyzed, the reflection led by the therapist, or simply by being home during the visit.

The intervention included weekly home visits during 
which the interaction between adults and children was video recorded. During session 1 two 10-minute videos were recorded of mother-child and father-child free play interactions respectively. They were instructed to play with your child as you normally do. Each dyad had a bag of toys that contained: cars, dolls, small balls, rattles, and other toys that could be added according to the child's preference.

In order to assess triadic interactions, the LTP videorecording procedure was followed (Fivaz-Depeursinge \& Corboz-Warnery, 1999). A small table was placed with three chairs, inviting mother, father, and child to sit forming a triangle. Again, they were asked to play as they normally do, but following four stages: i) Father or mother actively play with the child while the other is simply present; ii) Parents' roles are reversed; iii) Father, mother and child play actively; iv) Father and mother interact while the child is simply present. The triad was given three sets of three toys (puppets, cups and animals) and a clock so that they could organize their own to fulfill all stages in 10 to 15 minutes. This material was then analyzed to review clips of the film that showed positive relational aspects with the parents. The entire process included a total of seven sessions, two of which were used for assessments and five for video-feedback intervention with the father, mother or the parental couple.

The structure and aim of each session was the following.

\section{Session 1}

During this session, videos were recorded and questionnaires completed. The parents' concerns regarding their child's development or their relationship with their child were also explored.

\section{Post-session work}

After the first session, the psychotherapists analyzed the videos to identify negative and positive sequences that would be discussed with the parents in the following session. This procedure was followed after each session until the end of the intervention (Session 6).

\section{Sessions 2 and 3}

The father and mother participated in one session each; the order depended on what they had agreed to in Session 1. With each parent, the sequences selected from the dyadic play videos were reviewed. After the discussion and according to what the parent had discovered after observing him/herself in the video, a task was established for the parent to implement until the next session. The same procedure was followed with the other caregiver in Session 3. These sessions were conducted with one parent at a time in order to address specific aspects of the motherchild or father-child interaction related to the child's socio-emotional development difficulties.

\section{Session 4}

This session considered the parental couple, observing positive aspects of their triadic video.

\section{Session 5}

During this session, new videos were recorded. These included mother-child and father-child free play and a triadic feeding interaction.

\section{Session 6}

The videos recorded during Session 5 were discussed with the parental couple. The psychotherapists and the family evaluated the intervention, highlighting what they had learned throughout this process and providing an ending. This session - as well as session 4 - included both parents in order to strengthen co-parenting issues.

\section{Session 7}

Post-intervention assessment.

All sessions were conducted by the same pair of psychotherapists, except for the final evaluation session which was conducted by psychotherapists whom the family did not previously know, to prevent the bond with the clinicians from interfering with the results. The intervention also considered weekly group supervision where all videos were reviewed, scripts elaborated for the videofeedback sessions, and the main goals of the intervention were established. An accredited clinical supervisor, trained in the use of video-feedback, Video-feedback Intervention to promote Positive Parenting and Sensitive Discipline (Juffer, Bakermans-Kranenburg, \& van IJzendoorn, 2008) and two clinical psychologists who were also trained in the same technique supervised the team's clinical work. The diagram obtained from the larger study presents the procedure followed for the sessions: it is available from Olhaberry et al. (2017).

Each intervention was led by two psychotherapists with at least one semester of training in the use of video feedback with families and children under the age of three. The training entailed participating in weekly twohour clinical meetings as well as two days of training on infancy and toddlerhood, parenting and the use of the various measures considered in the study. The clinical team was formed by 18 psychotherapists, of whom six had previous experience using video feedback.

\section{Data analysis}

As the first analysis strategy, outliers and normality assumptions of the variables used in the parametric tests were assessed using the Kolmogorov-Smirnov test and Q-Q plots. The Kolmogorov-Smirnov test showed that 6 of the 13 studied variables had a normal distribution $(\mathrm{P}>.005)$. Dispersing the remaining 7 variables was evaluated as a function of the Q-Q plots, and the deviation was not sig- 
nificant, allowing for the use of parametric tests. A significance level of $\alpha=0.05$ was used. As a second strategy, a descriptive analysis of the relevant sociodemographic and clinical variables was conducted to perform $t$ tests for independent samples and $\chi^{2}$ tests to compare the groups and determine their homogeneity. Finally, to evaluate the effects of the intervention on child development, repeated measures ANOVA (rANOVA) were performed using the preand post-measurement as an intrasubject factor and the group to which it belonged as an intersubject factor. The assumption of homogeneity was evaluated with the Box test. Because there were two groups in the intersubjective factor and two measurements in the intrasubject factor, the sphericity assumption was not evaluated.

\section{Results}

\section{Descriptive analysis}

Both the EG and the CG comprised 40 homogeneous triads with regard to the age of the parents and the child and the education levels of the parents, which were evaluated by $t$-tests for independent samples, the details of which may be observed in Table 1 Homogeneity was also observed between the groups with regard to the place that the child occupied in the family, the parents' work day, attending daycare, breastfeeding and the presence of tracer conditions. To evaluate the homogeneity of the groups regarding these variables, $\chi^{2}$ tests were performed. These results are presented in Table 2. It is important to note that gender differences in the work day were observed in both groups, with fathers having a greater proportion of full time work than mothers $\left(\chi_{3}^{2}=24.916, \mathrm{P}=.000\right)$.

\section{Comparative analysis}

\section{Overall development measured with the Ages and Stages Questionnaires-3}

With regard to the Communication Area measured by the ASQ-3, the assumption of homogeneity (Box's $\left.M=4.349 ; F_{(3,1095120)}=1.409 ; \mathrm{P}=.238\right)$ was satisfied. There was also a significant interaction effect between the measurement and the group to which it belonged (Wilks $\lambda=0.948, F_{(1,78)}=4.284, \mathrm{P}=.042$ ) and a significant main effect of the measurement (Wilks $\lambda=0.422$, $\left.F_{(1,78)}=106.781, \mathrm{P}<.000\right)$. Although both groups of children improved their performance, the children in the EG

Table 1. Descriptive statistics of the participants' sociodemographic data.

\begin{tabular}{|c|c|c|c|c|c|c|}
\hline \multirow[t]{2}{*}{ Variable } & \multicolumn{2}{|c|}{ EG $n=40$} & \multicolumn{2}{|c|}{ CG $n=40$} & \multicolumn{2}{|c|}{ Mean Difference } \\
\hline & $M(S D)$ & Min. - Max. & $M(S D)$ & Min. - Max. & $T_{\text {observed }}$ & Sig. \\
\hline Mo age (years) & $M=32.83(S D=5.17)$ & $20-43$ & $M=31.70(S D=4.76)$ & $23-42$ & $T_{78}=1.012$ & .314 \\
\hline Fa age (years) & $M=35.63(S D=6.71)$ & $24-54$ & $M=33.70(S D=5.88)$ & $22-49$ & $T_{78}=1.365$ & .176 \\
\hline Child's age (months) & $M=25,08(S D=7.64)$ & $12-36$ & $M=24.15(S D=7.57)$ & $12-36$ & $T_{78}=0.547$ & .586 \\
\hline Mo Ed. (years) & $M=14.90(S D=2.55)$ & $7-17$ & $M=15.03(S D=2.82)$ & $8-17$ & $T_{78}=-.208$ & .836 \\
\hline Fa Ed. (years) & $M=15.05(S D=2.53)$ & $8-17$ & $M=15.13(S D=2.54)$ & $8-17$ & $T_{78}=-.132$ & .895 \\
\hline
\end{tabular}

EG, Experimental Group; CG, Control Group; M, Mean; SD, Standard Deviation; Sig., statistical significance; Mo, Mother; F, Father; Ed, Education.

Table 2. Frequency and percentages of the participants' sociodemographic data.

\begin{tabular}{|c|c|c|c|c|c|c|c|}
\hline \multicolumn{2}{|l|}{ Variable } & \multicolumn{2}{|c|}{ EG $n=40$} & \multicolumn{2}{|c|}{ CG $n=40$} & \multicolumn{2}{|c|}{ Goodness of Fit } \\
\hline & & $F$ & $\%$ & $F$ & $\%$ & $\chi_{\text {observed }}^{2}$ & Sig. \\
\hline \multirow[t]{4}{*}{ Birth order } & 1 & 29 & 72.5 & 28 & 70.0 & $\chi^{2}(3)=0.351$ & .950 \\
\hline & 2 & 8 & 20.0 & 8 & 20.0 & & \\
\hline & 3 & 2 & 5.0 & 2 & 5.0 & & \\
\hline & 4 & 1 & 2.5 & 2 & 5.0 & & \\
\hline \multicolumn{2}{|c|}{ Breastfeeding } & 37 & 92.5 & 39 & 97.5 & $\chi^{2}(1)=1.053$ & .305 \\
\hline \multicolumn{2}{|l|}{ Day care } & 24 & 68.6 & 19 & 48.7 & $\chi^{2}(1)=2.987$ & .084 \\
\hline \multicolumn{2}{|c|}{ Tracer diseases } & 14 & 35.0 & 15 & 37.5 & $\chi^{2}(1)=0.102$ & .750 \\
\hline \multicolumn{2}{|c|}{ Full-time work mother } & 18 & 58.1 & 21 & 67.7 & $\chi^{2}(1)=4.147$ & .246 \\
\hline \multicolumn{2}{|c|}{ Full-time work father } & 37 & 92.5 & 38 & 97.4 & $\chi^{2}(1)=1.334$ & .513 \\
\hline
\end{tabular}

EG, Experimental Group; CG, Control Group; f, frequency; \%, percentage. 
improved more than the children in the CG. Specifically, at the first evaluation, the CG children scored an average of -0.14 standard deviations from the cut-off point considered normal for their age $(\mathrm{SD}=0.97)$ at a mean of 1.24 $(\mathrm{SD}=1.35)$; the EG children improved their performance even further, averaging -0.47 on the first evaluation $(\mathrm{SD}=0.96)$ and an average of $1.60(\mathrm{SD}=1.22)$ on Evaluation 2 (Figure 1 and Table 3 ).

In the Fine Motor Area, the mixed ANOVA was consistent with the homogeneity assumption (Box's $M=1.348 ; F_{(3}$, $\left.{ }_{1095120)}=0.437 ; \mathrm{P}=.727\right)$, and an interaction effect was observed between the group and the evaluation (Wilks $\lambda=0.875$,
$\left.F_{(1,78)}=11.185 ; \mathrm{P}=.001\right)$. Specifically, children in the experimental group improved their performance from an average of 0.90 standard deviations from the cutoff that was considered normal $(\mathrm{SD}=0.30)$ to an average of $1.92(\mathrm{SD}=1.22)$ over the cutoff point. Children in the control group maintained their performance from an average of $0.93(\mathrm{SD}=0.27)$ to an average of $0.98(\mathrm{SD}=1.35)$ (Figure 1 and Table 3$)$.

Intervention does not affect a child's developmental capacity in the Problem Solving Scale, Personal-Social or Gross Motor areas. Details of the analyses of group comparison can be seen in Table 3 and the behavior of both analyses in Figure 1.

Table 3. Descriptive statistics of the child's development measured with the Ages and Stages Questionnaires-3.

\begin{tabular}{|c|c|c|c|c|c|c|c|}
\hline Variable ASQ-3 & $M E v .1 n=40$ & $M E v \cdot 2 n=40$ & Wilks' $\lambda$ & $F_{\text {observed }}$ & Sig. & Size Effect & Observed Power \\
\hline Comm. EG & $-0.47(\mathrm{SD}=0.96)$ & $1.60(\mathrm{SD}=1.22)$ & 0.948 & $F(1,78)=4.284$ & .042 & .052 & .534 \\
\hline Comm. CG & $-0.14(\mathrm{SD}=0.97)$ & $1.24(\mathrm{SD}=1.35)$ & & & & & \\
\hline Prob. Solv. EG & $1.43(\mathrm{SD}=0.99)$ & $1.72(\mathrm{SD}=1.14)$ & 0.998 & $F(1,78)=0.179$ & .673 & .002 & .070 \\
\hline Prob. Solv. CG & $1.27(\mathrm{SD}=1.06)$ & $1.43(\mathrm{SD}=1.11)$ & & & & & \\
\hline Pers-Soc. EG & $1.33(\mathrm{SD}=1.21)$ & $1.58(\mathrm{SD}=1.06)$ & 0.998 & $F(1,78)=0.156$ & .694 & .002 & .068 \\
\hline Pers-Soc. CG & $1.25(\mathrm{SD}=1.02)$ & $1.39(\mathrm{SD}=1.18)$ & & & & & \\
\hline Gross Mot. EG & $1.52(\mathrm{SD}=0.95)$ & $1.84(\mathrm{SD}=1.18)$ & 0.987 & $F(1,78)=1.035$ & .312 & .013 & .171 \\
\hline Gross Mot. CG & $1.87(\mathrm{~S} . \mathrm{D}=0.98)$ & $1.92(\mathrm{SD}=0.76)$ & & & & & \\
\hline Fin. Mot. EG & $0.90(\mathrm{SD}=0.30)$ & $1.92(\mathrm{SD}=1.22)$ & 0.875 & $F(1,78)=11.185$ & .001 & .125 & .910 \\
\hline Fin. Mot. CG & $0.93(\mathrm{SD}=0.27)$ & $0.98(\mathrm{SD}=1.35)$ & & & & & \\
\hline
\end{tabular}

ASQ-3, Ages and Stages Questionnaires-3; M Ev.1, Mean evaluation 1; M Ev.2, Mean evaluation 2; Sig., statistical significance; Comm., Communication; EG, Experimental Group; CG, Control Group; Prob. Solv., Problem Solving; Pers-Soc., Personal-Social; Gross Mot., Gross Motor; Fin. Mot., Fine Motor; SD, Standard Deviation.

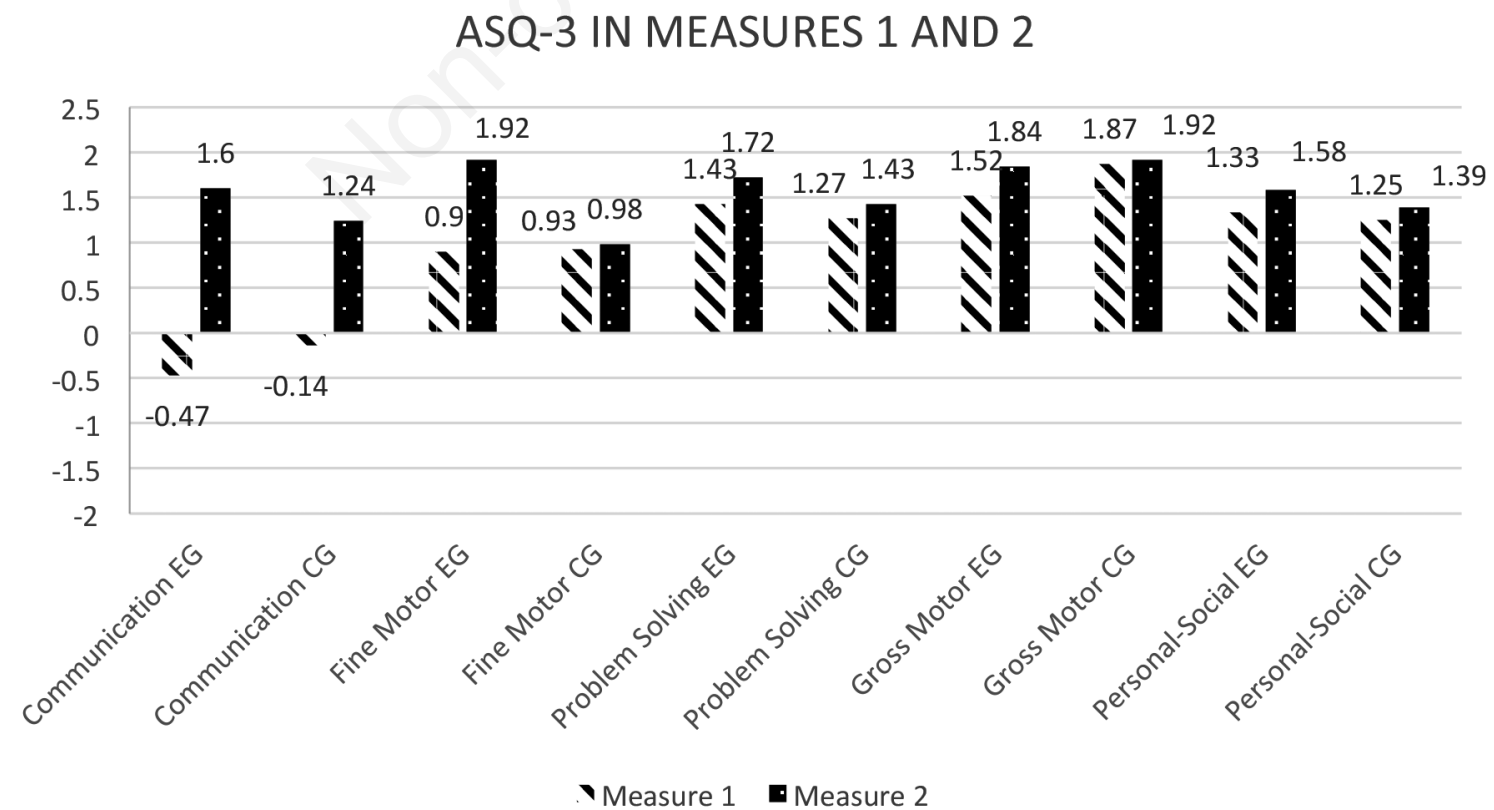

Figure 1. Effects of intervention on Ages and Stages Questionnaires-3 (ASQ-3) areas in experimental group (EG) and control group (CG). 
Social-emotional development measured with the Ages and Stages Questionnaires-SE

First, the effect of the intervention on the Global Percentage of Problems in Social-Emotional Development was evaluated. In the mixed ANOVA, the assumption of homogeneity (Box's $M=3.675 ; F_{(3,1095120)}=1.191 ; \mathrm{P}=.311$ ) was fulfilled, and it was observed that although the percentage of problems in the socio-emotional area decreased in the children of both groups, the decrease was even more significant in the EG than in the CG (Wilks' $\lambda=0.930$, $F(1,78)=5.907, \mathrm{P}=.017$ ) (Table 3). Specifically, the EG decreased from $18.08 \%$ for Assessment $1(\mathrm{SD}=11.05)$ to $12.07 \%$ for Assessment 2 ( $\mathrm{SD}=7.86$ ), while the $\mathrm{CG}$ showed no difference with $15.92 \%$ for Assessment 1 $(\mathrm{SD}=8.28)$ and $14.66 \%$ for Assessment $2(\mathrm{SD}=7.13)$. These results are shown in Figure 2.

The specific scales indicate that in the Percentage of Problems in Compliance, the assumption of homogeneity of variances was not met (Box's $M=11.992$; $\left.F_{(3,1095120)}=3.886 ; \mathrm{P}=.009\right)$. There was a significant interaction effect between the group and the measurement (Wilks' $\lambda=0.918, F_{(1,78)}=7.002 ; \mathrm{P}=.01$ ). Specifically, the $\mathrm{EG}$ children improved in this area from $23.75 \%$ in Measurement $1(\mathrm{SD}=23.54)$ to $8.75 \%$ in Measurement 2 $(\mathrm{SD}=14.61)$, whereas the $\mathrm{CG}$ showed no difference, with $13.79 \%(\mathrm{SD}=22.61)$ in Measurement 1 and $11.33 \%$ $(\mathrm{SD}=25.37)$ in Measurement 2 (Table 4).

In the Percentage of Problems in Interaction with People, the assumption of homogeneity of variances was also not met (Box's $M=10.055 ; F_{(3,1095120)}=3.259 ; \mathrm{P}=.021$ ), and a significant interaction effect was observed between the group and the measurement (Wilks' $\lambda=0.834$, $\left.F_{(1,78)}=15.523 ; \mathrm{P}<.000\right)$. In this case, the EG children improved from $16.20 \%(\mathrm{SD}=15.19)$ to $9.27 \%(\mathrm{SD}=9.26)$, whereas the $\mathrm{CG}$ children showed an increase in their problems from $10.11 \%(\mathrm{SD}=10.31)$ to $13.94 \%(\mathrm{SD}=11.30)$.

Significant intervention effects in the specific scales of Percentage of Problems in Self-regulation, Percentage of Problems in Communication, Percentage of Problems in Adaptive Functioning, Percentage of Problems in Autonomy, and Percentage of Problems in Affect were not observed $(\mathrm{P}>.05)$ (Table 4).

\section{Discussion and Conclusions}

As indicated by previous research on the benefits of video feedback in early intervention, its focused use in the mother-father-child triad demonstrated favorable outcomes in child development (Bakermans-Kranenburg et al., 2003; Pontoppidan, 2015; Pontoppidan et al., 2016; Riera, 2016; Salomonsson et al., 2015). This study also showed in socio-emotional and psychomotor development of children belonging to the EG in a global perspective. Improvement was found in many specific areas but not all. Regarding development there was a statistical significant increase in children's communication skills and fine motor skills. The improvement in communication may be explained by the focus of the intervention on

Table 4. Descriptive statistics of child development measured using the Ages and Stages Questionnaires-SE.

\begin{tabular}{|c|c|c|c|c|c|c|c|}
\hline Variable ASQ-SE & $M E v .1 n=40$ & $M E v .2 n=40$ & Wilks' $\lambda$ & $F_{\text {observed }}$ & Sig. & Size Effect & $\begin{array}{l}\text { Observed Power } \\
\end{array}$ \\
\hline Glob. Probl. EG & $18.08(\mathrm{~S} . \mathrm{D}=11.05)$ & $12.07(\mathrm{SD}=7.86)$ & 0.930 & $F(1,78)=5.907$ & .017 & .070 & .670 \\
\hline Glob. Probl. CG & $15.92(\mathrm{~S} . \mathrm{D}=8.28)$ & $14.66(\mathrm{SD}=7.13)$ & & & & & \\
\hline Self-reg. EG & 20.45 & - & - & - & - & - & - \\
\hline$(\mathrm{SD}=12.17)$ & 15.04 & - & & & & & \\
\hline$(\mathrm{SD}=12.54)$ & 0.980 & $\mathrm{~F}(1,78)=1.584$ & .212 & .020 & .237 & - & - \\
\hline Self-reg. CG & 21.81 & - & & & & & \\
\hline$(\mathrm{SD}=12.17)$ & 20.50 & - & - & - & - & - & - \\
\hline$(\mathrm{SD}=12.38)$ & & - & & & & & \\
\hline Comp. EG & 23.75 & - & - & - & - & - & - \\
\hline$(\mathrm{SD}=23.53)$ & 8.75 & - & & & & & \\
\hline$(\mathrm{SD}=14.61)$ & 0.918 & $F(1,78)=7.002$ & .010 & .082 & .743 & & - \\
\hline Comp. CG & 13.75 & - & & & & & \\
\hline$(\mathrm{SD}=22.61)$ & 13.33 & - & - & - & - & - & - \\
\hline$(\mathrm{S} . \mathrm{D}=25.37)$ & - & - & & & & & \\
\hline Adap. Func. EG & 19.26 & - & - & - & - & - & - \\
\hline$(\mathrm{SD}=18.65)$ & 14.28 & - & & & & & \\
\hline
\end{tabular}

ASQ-SE, Ages and Stages Questionnaires-SE; M Ev, Mean evaluation; Glob. Probl., Global Problem; EG, Experimental Group; CG, Control Group; SD, Standard Deviation; Self-reg., Self-regulation; Comp., Compliance; Adap. Func., Adaptive Functioning. 
dyadic and triadic family relationships and their effect on the child's communication skills. Enriching the interactional proposal parents offered to their children increased face-to-face contact, affective connection, use of verbal language, synchrony, and adjustment to the children's needs as well as interaction quality, positively affecting the child's communication skills (Greenspan et al., 2001).

In addition, improvements in the quality of triadic interactions during the first years of life have been associated with adequate child social development (Leidy et al., 2013; Raikes \& Thompson, 2006; Teubert \& Pinquart, 2010), which may also contribute to the development of communication skills in children. This is consistent with a previous study which reported that the EG from this sample improved their triadic interaction quality (Olhaberry et al., 2017). Therefore, fathers and mothers who can establish cooperative relationships that promote participation in a warm affective environment may promote childhood development.

The increase in fine motor skills in the children of the intervention group may be attributed to the improvement in affect regulation and behavior by increasing the quality of the dyadic relationships and the triadic interactions with the father and mother. In this sense, the literature demonstrates that children who participate in dysfunctional family interactions or with recurrent parental conflicts have difficulty developing adequate regulatory mechanisms (Cummings \& Davies, 2010; McHale, 2007). Thus, focusing on family interactions and their consequent improvement contributes to improving children's regulatory mechanisms.
The development of fine motor skills requires longer periods of concentration and focus, which may be interfered by self-regulation difficulties. In this sense, achieving adequate regulatory mechanisms may be a prerequisite for developing the attention and concentration necessary for practices associated with greater coordination and precise hand movements that fine motor skills require. In fact, the literature has indicated that the development of fine motor function is closely related to the development of executive function, an ability involved in attentional change, working memory and inhibitory control (Cameron et al., 2012).

These effects are consistent with a significant global improvement in socioemotional development in children in the EG as well as improvement in some subscales. Specifically, compliance and interaction with people improved only in the EG; whereas in the $\mathrm{CG}$, the former remained the same and the latter became worse. These two subscales can be directly related to the quality of family interactions, an aspect that was a main goal of the intervention. In fact, compliance alludes to the obedience of the child and its ability to follow everyday rules at home. Interaction with others considers the child's ability to respond and/or initiate social responses with parents, other adults or peers in typical situations. These results indicate that the intervention improves and enriches daily interactions within the families, offering an opportunity to take advantage of the instances that already exist (food, diaper-changing, tidy-up time, play).

Regarding the improvements observed in socio-emotional development, the areas showing an increase

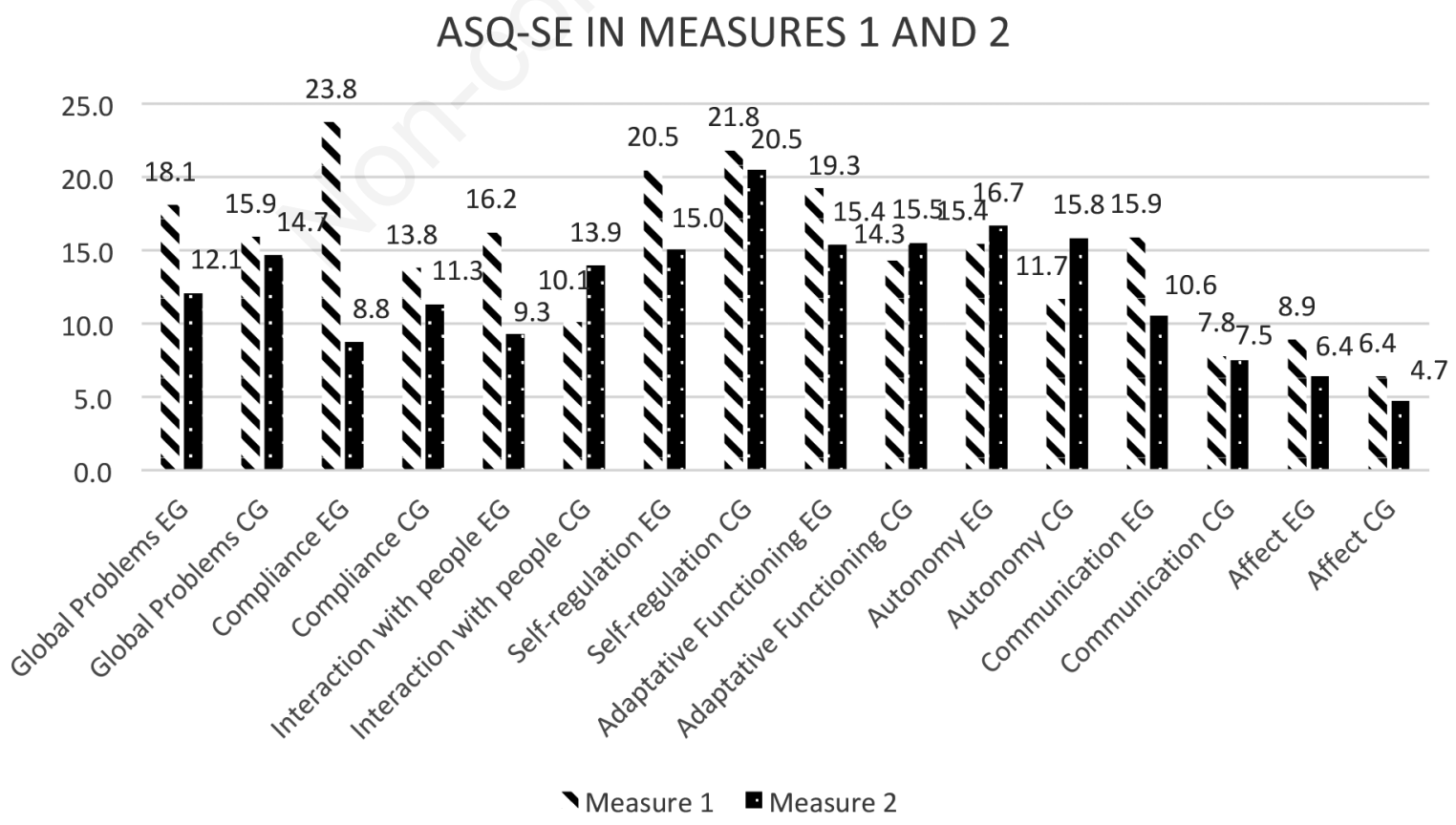

Figure 2. Percentage of problems in Ages and Stages Questionnaires-SE (ASQ-SE) in experimental group (EG) and control group (CG). 
coincide with those reported in previous studies that also assessed socio-emotional development with ASQ-SE (Hoivik et al., 2015). These showed improvements in the areas of self-regulation, autonomy, adaptive functioning and affect, -that were not found in the present study-, as well as similar results in compliance and interaction with others. However, the present study obtained its results immediately after the intervention, whereas in the aforementioned study these were achieved at the 6 month follow-up. Differences between of the results between our study and Hoivik's may be explained due to the temporality of the assessment, as well as the amplifications of those changes at follow-up in Hoivik's study.

It is likely that the first aspects to show change concern elements directly associated with interactional practices, such as following instructions, completing a task, sharing an activity, taking turns speaking and sharing positive affect. In this sense, such exchanges may form the basis for those internal changes that could require more time to establish, such as self-regulation, which is also associated with adequate autonomy and affect management. It may be hypothesized, then, that these changes may also be expressed in the children studied once the changes in their triadic interactions are consolidated with practice over time.

The presence of significant changes immediately following the end of the intervention may also be explained by the inclusion of the triad, with the simultaneous participation of the father and the mother. In this sense, the intervention may have an influence at different levels, including the dyadic interactions of the child with his mother and his father separately but also in the triadic interactions that create different emotional and bonding experiences. The dyadic and triadic subsystems within the family mutually influence each other in a non-linear manner, allowing to observe parents with difficulties in their relationship with their partner who can achieve adequate dyadic interactions with their children, as well as parents in satisfactory couple relationships who exhibit deficits in dyadic interactions or in triadic interactions with their children.

The video-feedback intervention employed in this study is a short-term, cost-effective intervention that is able to promote changes in early childhood development. One of its qualities lies in the use of home visits. Home visits allow the child to be observed in his/her daily context, favors a diagnostic understanding, and contributes to adherence because the family is not required to leave their home. This facilitates a greater regularity of sessions and a stronger therapeutic alliance insofar the home visits promote a trusting relationship with the family. The psychotherapeutic work developed in family homes, alongside the focused interventions and specific goals, facilitates a feeling of achievement and satisfaction in parents as it promotes a sense of competency in their parental role.

Qualitative studies aiming to explain video feedback participant's experiences highlight the increase of self-efficacy feelings, better satisfaction and self-esteem in their parental role, as well as improvements in their parental practices (Doria et al., 2014). From the observation, the use of video feedback favors a reflective stance, enhancing existing parental abilities that at the same time enhance children's development. In this stance, the resource-focus approach from both caregivers and children also aims to facilitate that caregivers discover and strengthen themselves from a different and positive perspective.

\section{Limitations}

Within the limitations of the study, there is a lack of randomization in the allocation of the participating families to the groups and a lack of follow-up measurements. In future studies, it would be important to repeat the measurements 6 months after the intervention to assess the permanence of the observed changes and the appearance of modifications in other areas of development.

\section{References}

Bakermans-Kranenburg, M. J., van IJzendoorn, M. H., \& Juffer, F. (2003). Less is more: Meta-analyses of sensitivity and attachment interventions in early childhood. Psychological Bulletin, 129, 195-215. doi: 10.1037/00332909.129.2.195

Benz, M., \& Scholtes-Spang, K. (2015). From normal development to development crisis and regulatory disorder. In M. Cierpka (Ed.), Regulatory disorders in infants, assessment, diagnosis and treatment (pp. 1-15). Switzerland: Springer.

Bian, X., Xie, H., Squires, J., \& Chen, C. Y. (2017). Adapting a parent-completed, socioemotional questionnaire in china: the ages \& stages questionnaires: social-emotional. Infant Mental Health Journal, 38, 258-266. doi: 10.1002/ imhj. 21626

Bouvette-Turcot, A.-A., Bernier, A., \& Leblanc, É. (2017). Maternal psychosocial maladjustment and child internalizing symptoms: Investigating the modulating role of maternal sensitivity. Journal of Abnormal Child Psychology, 45(1), 157-170. doi: 10.1007/s10802-016-0154-8

Briggs, R. D., Stettler, E. M., Silver, E. J., Schrag, R. D. A., Nayak, M., Chinitz, S., \& Racine, A. D. (2012). Social-emotional screening for infants and toddlers in primary care. $\mathrm{Pe}$ diatrics, 129, e377-e384. doi: 10.1542/peds.2010-2211

Briggs-Gowan, M. J., Carter, A., Irwin, J., Wachtel, K., \& Cicchetti, D. (2004). The brief infant-toddler social and emotional assessment: Screening for social-emotional problems and delays in competence. Journal of Pediatric Psychology, 29, 143-155. doi: 10.1093/jpepsy/jsh017

Briggs-Gowan, M. J., Carter, A. S., McCarthy, K., Augustyn, M., Caronna, E., \& Clark, R. (2013). Clinical validity of a brief measure of early childhood social-emotional/behavioral problems. Journal of Pediatric Psychology, 38, 577587. doi: 10.1093/jpepsy/jst014

Cameron, C. E., Brock, L. L., Murrah, W. M., Bell, L. H., Worzalla, S. L., Grissmer, D., \& Morrison, F. J. (2012). Fine motor skills and executive function both contribute to kindergarten achievement. Child Development, 83, 1229- 
1244. doi: 10.1111/j.1467-8624.2012.01768.x

Caselman, T. D., \& Self, P. A. (2008). Assessment instruments for measuring young children's social-emotional behavioral development. Children \& Schools, 30(2), 103-115. doi: $10.1093 / \mathrm{cs} / 30.2 .103$

Centro de Microdatos - Universidad de Chile (2010). Encuesta Longitudinal de Primera infancia. Santiago: University of Chile. Retrieved from: http://www.superacionpobreza.cl/wpcontent/uploads/2014/03/documento_metodologico.pdf

Centro de Microdatos-Universidad de Chile. (2014). Encuesta longitudinal de primera infancia [Longitudinal early childhood survey]. Santiago: University of Chile.

Cicchetti, D. (1990). An organizational perspective on attachment beyond infancy: Implications for theory, measurement, and research. In M. T. Greenberg, D. Cicchetti, \& E. M. Cummings (Eds.), Attachment in the preschool years: Theory, research, and intervention (pp. 3-49). Chicago: University of Chicago Press.

Crittenden, P. (2006). A dynamic-maturational model of attachment. Australian and New Zealand Journal of Family Therapy, 27(2), 105-115. doi: 10.1002/j.1467-8438.2006. tb00704.x

Cummings, E. M., \& Davies, P. T. (2010). Marital conflict and children: An emotional security perspective. New York, NY: Guilford Publications.

De Wolff, M. S., Theunissen, M. H. C., Vogels, A. G. C., \& Reijneveld, S. A. (2013). Three questionnaires to detect psychosocial problems in toddlers: A comparison of the BITSEA, ASQ:SE, and KIPPPI. Academic Pediatrics, 13, 587-592. doi: 10.1016/j.acap.2013.07.007

Delucchi, N. S., Quinteros, M. M., Muzzio, E. G., \& Álvarez, M. P. S. (2009). Terapia de interacción guiada: Una nueva modalidad de intervención con familias multiproblemáticas y en riesgo social [Guided interaction therapy: A new modality of intervention with multiproblematic families at social risk]. Terapia Psicológica, 27, 203-213. doi: 10.4067/S0718-48082009000200006

Doria, M. V., Kennedy, H., Strathie, C., \& Strathie, S. (2014). Explanations for the success of video interaction guidance (VIG): An emerging method in family psychotherapy. Family Journal, 22(1), 78-87. doi: 10.1177/1066480713505072

Engfer, A. (1988). The interrelatedness of marriage and the mother-child relationship. In R. Hinde \& J. Stevenson-Hinde (Eds.), Relationships within families: Mutual influences (pp. 104-118). New York: Oxford University Press.

Favez, N., Frascarolo, F., Keren, M., \& Fivaz-Depeursinge, E. (2009). Principles of family therapy in infancy. In C. Zeanah (Ed.), Handbook of infant mental health (pp. 468-484). New York, NY: Guilford Press.

Feldman, R., \& Masalha, S. (2010). Parent-child and triadic antecedents of children's social competence: Cultural specificity, shared process. Developmental Psychology, 46, 455-467. doi: 10.1037/a0017415

Fincham, F. D. (1998). Child development and marital relations. Child Development, 69, 543-574. doi: 10.1111/j.14678624.1998.tb06207.x

Fivaz-Depeursinge, E., \& Corboz-Warnery, A. (1999). The primary triangle: A developmental systems view of mothers, $f a-$ thers, and infants. London, UK: Basic Books.

Fukkink, R. G. (2008). Video feedback in widescreen: A metaanalysis of family programs. Clinical Psychology Review, 28, 904-916. doi: 10.1016/j.cpr.2008.01.003

Greenspan, S. I. (2007). Great kids: Helping your baby and child develop the ten essential qualities for a healthy, happy life. Philadelphia, PA: Hachette.

Greenspan, S., DeGangu, G., \& Wieder, S. (2001). The functional emotional assessment scale (FEAS) for infancy and early childhood: Clinical and research applications. Bthesda, MD: Interdisciplinary Council on Developmental and Learning Disorders.

Groeneveld, M. G., Vermeer, H. J., van Ijzendoorn, M. H., \& Linting, M. (2016). Randomized video-feedback intervention in home-based childcare: Improvement of children's wellbeing dependent on time spent with trusted caregiver. Child \& Youth Care Forum, 45, 587-606. doi: 10.1007/ s10566-015-9344-8

Hart, B., \& Risley, T. R. (1995). Meaningful differences in the everyday experience of young American children. Baltimore, MD: Brookes.

Hoivik, M., Lydersen, S., Drugli, M., Onsøien, R., Hansen, M., \& Nielsen, T. (2015). Video feedback compared to treatment as usual in families with parent-child interactions problems: A randomized controlled trial. Child and Adolescent Psychiatry and Mental Health, 9(1), 3. doi: 10.1186/s13034-0150036-9

Juffer, F., Bakermans-Kranenburg, M., \& van IJzendoorn, M. (2008). Promoting positive parenting, an attachment-based intervention. New York: Psychology Press, Taylor \& Francis Group.

Kalinauskiene, L., Cekuoliene, D., Van Ijzendoorn, M. H., Bakermans-Kranenburg, M. J., Juffer, F., \& Kusakovskaja, I. (2009). Supporting insensitive mothers: The Vilnius randomized control trial of video-feedback intervention to promote maternal sensitivity and infant attachment security. Child: Care, Health and Development, 35, 613-623. doi: 10.1111/j.1365-2214.2009.00962.x

Kim, H. M.-S. (2012). The role of maternal verbal sensitivity during parent-child shared book reading in socio-emotional functioning in the preschool years (Doctoral Thesis). Rutgers The State University of New Jersey, New Brunswick.

Leidy, M., Schofield, T., \& Parke, R. (2013). Fathers' contributions to children's social development. In N. J. Cabrera \& C. S. Tamis-LeMonda (Eds.), Handbook of father involvement: Multidisciplinary perspectives (1st ed., pp. 151-167). New York, NY: Routledge.

McHale, J. P. (2007). When infants grow up in multiperson relationship systems. Infant Mental Health Journal, 28, 370392. doi: 10.1002/imhj.20142

McHale, J. P., Favez, N., Fivaz-Depeursinge, E. (2018). The Lausanne Trilogue Play paradigm: Breaking discoveries in family process and therapy. Journal of Child and Family Studies, 27, 3063-3072. doi: 10.1007/s10826-018-1209-y

Moss, E., Dubois-Comtois, K., Cyr, C., Tarabulsy, G. M., St-Laurent, D., \& Bernier, A. (2011). Efficacy of a home-visiting intervention aimed at improving maternal sensitivity, child attachment, and behavioral outcomes for maltreated children: A randomized control trial. Development and Psychopathology, 23(1), 195-210. doi: 10.1017/ s0954579410000738

Olhaberry, M., León, M. J., Escobar, M., Iribarren, D., MoralesReyes, I., \& Álvarez, K. (2017). Video-feedback intervention to improve parental sensitivity and the quality of interactions in mother-father-infant triads. Mental Health in Family Medicine, 13, 532-543. doi: 10.25149/17568358.1304029

Olhaberry, M., León, M. J., Seguel, M., \& Mena, C. (2015). Video-feedback intervention in mother-baby dyads with de- 
pressive symptomatology and relationship difficulties. Research in Psychotherapy: Psychopathology, Process and Outcome, 18(2), 82-92. doi: 10.4081/ripppo.2015.177

Papalia, D. E., \& Feldman, R. D. (2012). Desarrollo humano [Human development] (12th ed.). Santiago, Chile: McGraw Hill Education.

Parke, R. D. (1996). Fathers (Vol. 33). Cambridge, MA: Harvard University.

Planalp, E. M., \& Braungart-Rieker, J. M. (2013). Temperamental precursors of infant attachment with mothers and fathers. Infant Behavior and Development, 36, 796-808. doi: 10.1016/j.infbeh.2013.09.004

Pontoppidan, M. (2015). The effectiveness of the incredible years parents and babies program as a universal prevention intervention for parents of infants in Denmark: Study protocol for a pilot randomized controlled trial. Trials, 16, 386397. doi: 10.1186/s13063-015-0859-y

Pontoppidan, M., Klest, S. K., \& Sandoy, T. M. (2016). The incredible years parents and babies program: A pilot randomized controlled trial. PLoS One, 11, e0167592. doi: 10.1371/journal.pone.0167592

Raikes, H. A., \& Thompson, R. A. (2006). Family emotional climate, attachment security and young children's emotion knowledge in a high risk sample. British Journal of Developmental Psychology, 24(1), 89-104. doi: 10.1348/ $026151005 \times 70427$

Riera, J. (2016). Improving quality of mother-child relationship and their attachment, as a factor of mental health: A systematic review of interventions. Barcelona, Spain: University of Barcelona.

Salomonsson, M. W., Sorjonen, K., \& Salomonsson, B. (2015). A long-term follow-up study of a randomized controlled trial of mother-infant psychoanalytic treatment: Outcomes on mothers and interactions. Infant Mental Health Journal, 36, 542-555. doi: 10.1002/imhj.21536

Schonhaut, B., \& Armijo, I. (2014). Aplicabilidad del ages \& stages questionnaires para el tamizaje del desarrollo psicomotor [Applicability of ages \& stages questionnaires for the screening of psychomotor development]. Revista Chilena de Pediatría, 85(1), 12-21. doi: 10.4067/s037041062014000100002

Schonhaut, L., Armijo, I., Millán, T., Herreros, J., Hernández, K., Salgado, A. M., \& Cordero, M. Á. (2010). Comparación de la evaluación tradicional del desarrollo psicomotor versus una prueba autoadministrada [Comparison of traditional assessment of psychomotor development versus a self-administered test]. Revista Chilena de Pediatría, 81, 498-505. doi: 10.4067/s0370-41062010000600003

Schonhaut, L., Armijo, I., Schönstedt, M., Alvarez, J., \& Cordero, M. (2013). Validity of the Ages and Stages Questionnaires in term and preterm infants. Pediatrics, 131, e1468-e1474. doi: 10.1542/peds.2012-3313

Shonkoff, J. P., Phillips, D. A., \& National Research Council. (2000). From neurons to neighborhoods: The science of early childhood development. Washington, DC: National Academies Press.

Sidor, A., Fischer, C., Eickhorst, A., \& Cierpka, M. (2013). In- fluence of early regulatory problems in infants on their development at 12 months: A longitudinal study in a high-risk sample. Child and Adolescent Psychiatry and Mental Health, 7(1), 35. doi: 10.1186/1753-2000-7-35

Sirin, S. R. (2005). Socioeconomic status and academic achievement: A meta-analytic review of research. Review of Educational Research, 75, 417-453. doi: 10.3102/ 00346543075003417

Squires, J., Bricker, D., \& Twombly, E. (2002). Ages \& stages questionnaires: Socialemotional (ASQ:SE): A parent-completed, child-monitoring system for socialemotional behaviors. Baltimore, MD: Brookes.

Squires, J., Bricker, D., \& Twombly, E. (2003). The ASQ: SE user's guide for the ages \& stages questionnaires, socialemotional: A parent completed, child-monitoring system for social-emotional behaviors. Baltimore, MD: Brookes.

Squires, J., Bricker, D., \& Twombly, E. (2004). Parent-completed screening for social emotional problems in young children: The effects of risk/disability status and gender on performance. Infant Mental Health Journal, 25(1), 62-73. doi: 10.1002/imhj.10084

Squires, J., Bricker, D., \& Twombly, E. (2014). Ages \& stages questionnaires: Social-emotional (ASQ:SE): A parent-completed, child-monitoring system for social-emotional behaviors. Baltimore, MD: Brookes.

Squires, J., Twombly, E., Bricker, D. D., \& Potter, L. W. (2009). ASQ-3 user's guide (3rd ed.). Baltimore, MD: Paul H. Brookes Pub.

Sroufe, L. A. (1996). Emotional development: The organisation of emotional life in the early years (Cambridge studies in social and emotional development). New York, NY: Cambridge University Press.

Teubert, D., \& Pinquart, M. (2010). The association between coparenting and child adjustment: A meta-analysis. Parenting, 10, 286-307. doi: 10.1080/15295192.2010.492040

Thompson, R. A. (2001). Development in the first years of life. Future of Children, 11(1), 20-33. doi: 10.2307/1602807

Tissot, H., Favez, N., Frascarolo, F., \& Despland, J. N. (2016). Coparenting behaviors as mediators between postpartum parental depressive symptoms and Toddler's symptoms. Frontiers in Psychology, 7, 1912. doi: 10.3389/fpsyg. 2016.01912

Van Zeij1, J., Mesman, J., Van Ijzendoorn, M. H., BakermansKranenburg, M. J., Juffer, F., Stolk, M. N., \& Alink, L. R. A. (2006). Attachment-based intervention for enhancing sensitive discipline in mothers of 1- to 3-year-old children at risk for externalizing behavior problems: A randomized controlled trial. Journal of Consulting and Clinical Psychology, 74, 994-1005. doi: 10.1037/0022-006x.74.6.994

Wendland, J., Danet, M., Gacoin, E., Didane, N., Bodeau, N., Saïas, T., ... Chirac, O. (2014). French Version of the Brief Infant-Toddler Social and Emotional Assessment Questionnaire-BITSEA. Journal of Pediatric Psychology, 39, 562575. doi: 10.1093/jpepsy/jsu016 